\title{
IMMUNOHISTOCHEMICAL DIAGNOSIS OF THE VIABILITY OF THE STRANGULATION FURROW
}

\author{
Vadym Dudnyk \\ Department of Forensic-medical examination \\ Kharkiv Medical Academy of Postgraduate Education \\ 58 Amosova str., Kharkiv, Ukraine, 61176 \\ 78vadson87@gmail.com
}

\begin{abstract}
The aim of the research was to study the possibility of using immunohistochemical markers for the diagnosis of intravital stangulation.

Materials and methods: Fragments of the neck skin from the strnaglulation zone were selected as objects of research. The main study group included 20 deaths due to hanging (10 men and 10 women). For the control group, 10 cases of acute coronary death (5 men and 5 women) were used. Using a complex of IHC markers, the labeling of the epidermis and epithelial structures, the features of cellular immune responses, the manifestation of oxidative steress were studied.

Results: Peculiarities of morphological manifestations of strangulation furrow in mechanical asphyxia were studied. It is established that the key link of its morphogenesis is impaired vascular wall permeability with loss of type IV collagen in the basement membranes of epithelium and skin vessels, migration into tissues of activated CD15 + granulocytes, CD68 + macrophages and CD117 + labrocytes, endothelial nitric oxide synthase (eNOS), inducible nitric oxide synthase (iNOS), fibrinogen protein and transforming growth factor $\beta 1$.

Conclusion: Such changes in the tinctorial properties of skin and subcutaneous adipose tissue can be recorded by immuno histochemical (IHC) and serve as an important diagnostic criterion for the viability of the formation of the strangulation furrow.

Keywords: strangulation furrow, immunohistochemical criteria of viability, forensic examination, mechanical asphyxia, hanging.
\end{abstract}

DOI: $10.21303 / 2504-5679.2021 .001825$

\section{Introduction}

According to modern requirements for forensic examinations of corpses, almost no carefully conducted expert examination of the corpse can acquire maximum probative value without appropriate laboratory and additional research methods [1]. To address the issues that arise before the forensic expert during the examination of the corpse in the case of strangulation asphyxia, such as determining the cause of death, determining the nature and mechanism of neck injuries, establishing the viability and time of their cause, microscopic, namely histological, research methods are widely used in expert practice [2].

In the skin, the main morphological features of local compression are: general flattening and thinning of the skin or its surface areas; defects of the stratum corneum of the skin, formed by deposition; blurring or uncertainty of the boundaries between the layers of the epidermis and individual keratinocytes; hyperchromia and deformation of keratinocyte nuclei, which take the form of oval to rod-shaped, and are mainly oriented parallel to the skin surface; deformation of skin appendages in the form of their general flattening and changes of nuclei of cells, similarly to keratinocytes. Signs of local reactions that may indicate the viability of the injury include: redness of blood vessels and perivascular hemorrhage on both sides of the strangulation furrow; swelling of the dermis; violation of the rheological properties of blood in the form of thrombosis; manifestations of immune system reactions (leukostasis and accumulation of neutrophils in the vascular endothelium, the release of neutrophils outside the vessels into the vascular space), etc. [3].

Unfortunately, traditional morphological methods of examination of tissues removed during autopsy have certain shortcomings in determining the dynamics of tissue reactions. Therefore, in recent years, forensic experts are looking for newer and more reliable in terms of evidence-based medicine methods for diagnosing the survival of the formation of strangulation furrows [4].

Data on the use of IHC markers to study this problem are isolated, mainly in the works of scientists from China, Japan, USA and indicate the possibility and feasibility of their use $[5,6]$. 
The aim of the study to determine the diagnostic criteria for forensic diagnosis of lifelong origin of the strangulation furrow on the basis of the use of a set of IHC markers.

\section{Material and methods}

The studies were carried out in the immunohistochemical laboratory on the basis of the Department of Pathological Anatomy of the Kharkov Academy of Postgraduate Education.

Research period: December 2020 - February 2021.

The IHC method was used to detail morphological changes in the skin, lungs, and substance of the brain and to establish criteria for the viability of the strangulation furrow. The I (main) group included autopsy material of 20 cases of strangulation asphyxia (10 men and 10 women aged 30 to 65 years, average age $43.1 \pm 0.2$ ). As a control group (II), section material of 10 observations of deaths from acute coronary death ( 5 men and 5 women aged 30 to 65 years average age $48.9 \pm 0.3$ ) was studied. Fragments of skin from the zones of strangulation furrow were fixed in $10 \%$ solution of neutral formalin buffered with phosphate buffer, subjected to standard wiring with increasing concentrations of ethanols, chloroform, filled with paraffin. From paraffin blocks were made serial sections with a thickness of 3-4 $\mu \mathrm{m}$, which were applied to highly adhesive glasses Super Frost and dried at $37{ }^{\circ} \mathrm{C}$ for 18 hours. Unmasking heat treatment was performed by boiling the sections in citrate buffer ( $\mathrm{pH}$ 6.0-7.4). UltraVision Quanto Detection Systems HRP Polymer (Thermo scientific, Germany) was used to visualize primary antibodies. DAB (diaminobenzidine) was used as the chromogen.

Labeling of the epidermis and other epithelial structures was detected using monoclonal antibodies (MCAB) to Cytokeratin pan [AE1/AE3]. Peculiarities of immune cellular reactions in areas of skin damage were determined using monoclonal antibodies (MCAB) to CD68 macrophages, granular leukocytes CD15, mast cells CD117. To study the manifestations of oxidative stress in conditions of asphyxia, the expression of markers of nitric oxide metabolism - endothelial nitric oxide synthase (eNOS), inducible nitric oxide synthase (iNOS) and transforming growth factor TGF- $\beta 1$ (polyclonal antibodies) was detected. The basement membranes of blood vessels and epithelial coverings were labeled with type IV collagen (MCAB to Collagen IV). The presence of fibrinogen exudation in the compression zone was detected by the expression of MCAB to Fibrinogen. The list of used primary antibodies with the indication of the manufacturer and the titer are presented in the table (Table 1).

\section{Table 1}

List of primary antibodies for IHC study

\begin{tabular}{|c|c|c|c|c|}
\hline No. & Name of IGH antibody & Localization in the cell & Manufacturer & Antibody titer \\
\hline 1 & $\begin{array}{l}\text { Fibrinogen gamma Recombinant Rabbit } \\
\text { Monoclonal Antibody (JG37-18) }\end{array}$ & Cytoplasm & Thermo scientific, Germany & $1: 50$ \\
\hline 2 & TGF- $\beta$ 1/3 Receptor Ab-3 & $\begin{array}{l}\text { Cell membrane and } \\
\text { cytoplasm }\end{array}$ & Thermo scientific, Germany & Ready-to-Use \\
\hline 3 & CD15 Ab-3, Mouse Monoclonal Antibody & $\begin{array}{l}\text { Cell membrane and cyto- } \\
\text { plasm (paranuclear staining) }\end{array}$ & $\begin{array}{l}\text { Thermo Scientific } \\
\text { TMLab Vision }\end{array}$ & $1: 100$ \\
\hline 4 & CD68 (KP1) & Cell membrane & Termo Scientific, USA & Ready-to-Use \\
\hline 5 & $\begin{array}{l}\text { CD117/c-Kit Mouse Monoclonal } \\
\text { Antibody (1C5) } \\
\text { Cell membrane and cytoplasm }\end{array}$ & $\begin{array}{l}\text { Cell membrane and } \\
\text { cytoplasm }\end{array}$ & Thermo scientific, Germany & $1: 200$ \\
\hline 6 & $\begin{array}{l}\text { Nitric Oxide Synthase, inducible (iNOS), } \\
\text { Rabbit Polyclonal Antibody }\end{array}$ & Cytoplasm & Thermo scientific, Germany & $1: 100$ \\
\hline 7 & $\begin{array}{l}\text { Nitric Oxide Synthase, endothelial } \\
\text { (eNOS), Rabbit Polyclonal Antibody }\end{array}$ & Cytoplasm & Thermo scientific, Germany & $1: 50$ \\
\hline 8 & Collagen IV (CIV22), Mouse Monoclonal & Cytoplasm & DAKO, Denmark & $1: 50$ \\
\hline 9 & $\begin{array}{l}\text { Anti-pan Cytokeratin antibody [AE1/AE3], } \\
\text { Mouse Monoclonal }\end{array}$ & $\begin{array}{l}\text { Cell membrane and } \\
\text { cytoplasm }\end{array}$ & Abcam, Great Britain & $1: 50$ \\
\hline
\end{tabular}


A semi-quantitative scale was used to assess IHC label. The results were calculated using the Avtandilov eyepiece [7] in 10 randomly selected fields of view at a magnification of $\times 400$. The IHC label was evaluated by the degree of distribution and intensity of brown staining in micropreparations: negative ( 0 ) was considered a reaction in the absence of staining of specific cell structures, weak positive $(1+)$ was considered a reaction with weak or focal staining from 0 to $30 \%$ of cells, moderate positive $(2+)$ - at sufficient or focal staining of $30-60 \%$ of cells, the reaction at staining of $60-90 \%$ of cells was considered expressed or diffusion (3+).

A set of immunohistochemical studies was performed on a Primo Star microscope (Carl Zeiss, Germany) using the AxioCam program (ERc 5s).

\section{Results}

In the IHC study of skin fragments, we found the following. Cells of thinned layers of the epidermis with deformed flattened keratinocytes in all cases of observation group I showed weak and uneven cytoplasmic expression of low molecular weight cytokeratins (Fig. 1, a, b).

In the observations of group II (control) the expression of Cytokeratin pan in the epidermis and epithelial cells of the glands was not reduced, the staining of both cytoplasm and cell membrane was pronounced $(3+)$, due to which the boundaries between epitheliocytes were clear, sometimes emphasized (Fig. 1, $\boldsymbol{b}, \boldsymbol{d}$ ).

In the drugs of group I, we found a very pronounced inflammatory infiltrate not only in the above areas, but also in the subepidermal stroma of the skin. All infiltrate cells were 3-4 times larger than mature $\mathrm{T}$ lymphocytes, had a large nucleus and a pronounced granular cytoplasm. Therefore, in our work we used markers for granulocytes, macrophages and labrocytes.

$\mathrm{CD} 15+$ neutrophils are able to function in oxygen-poor tissues because they receive energy through glycolysis and have large glycogen stores [8], so they are the first to appear in the area of compression in strangulation asphyxia (Fig. 2).

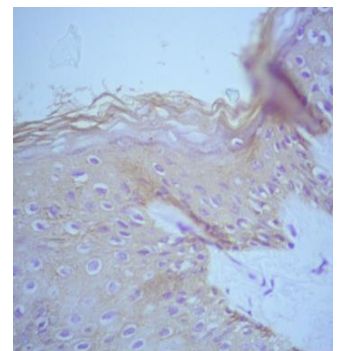

$a$

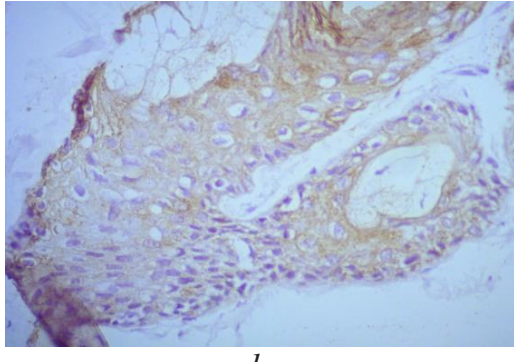

$b$

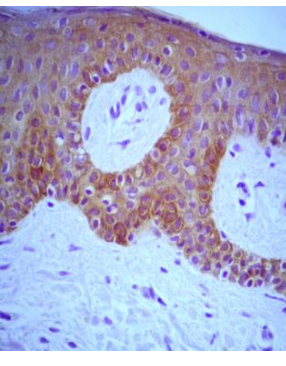

c

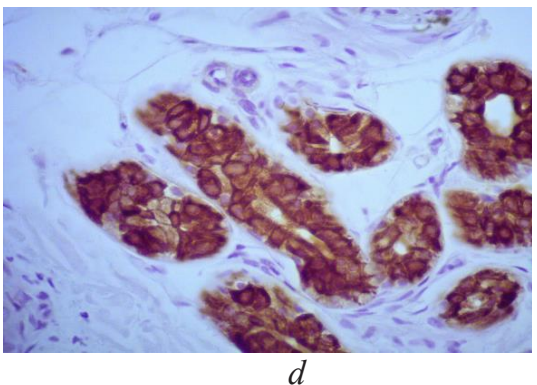

Fig. 1. Weak, uneven expression of Cytokeratin pan: $a$ - in thinned deformed epidermis; $b$ - in deformed sebaceous gland cells, study group I. Expressed expression of Cytokeratin pan; $c$ - in the epidermis; $d$ - in the epitheliocytes of sweat glands, group II study.

Reaction from MCAB to Cytokeratin pan [AE1/AE3], $\times 400$

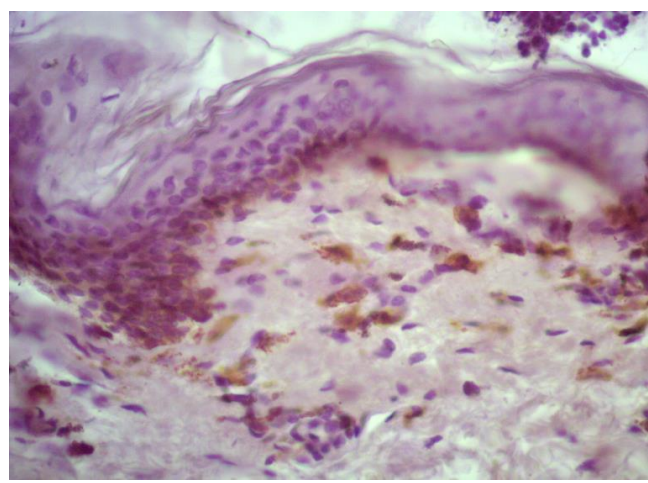

Fig. 2. Multiple CD15 + skin granulocytes, study group I. Reaction from MCAB to CD15 Ab-3. $\times 400$ 
In the fragments of the skin of the strangulation furrow of group I CD68 + macrophages were found in the subepidermal zones, in the dermis on the border with intact skin, in places of accumulation of lymphocytes. Single macrophages were found in the hypodermis (Fig. 3).

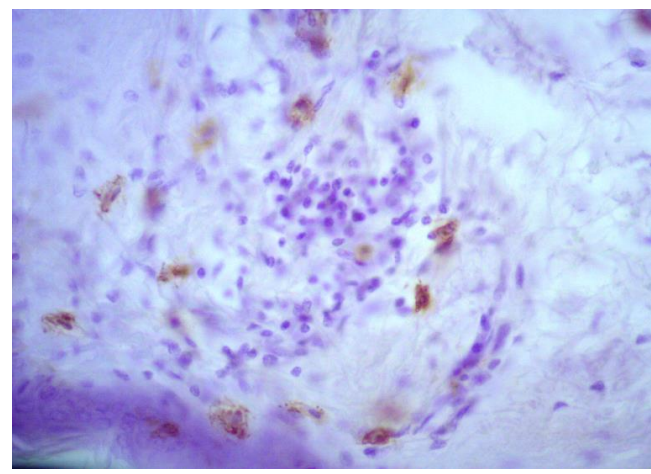

Fig. 3. CD68 + macrophages and T-lymphocytes of the dermis, group I study.

Reaction from MCAB to CD68 (CR1), $\times 400$

In group I of the study there was a clear trend of location of mast cells along blood vessels and nerves. They were also found in large numbers under the epidermis (Fig. 4). In some cases, weak staining of dermal fibers was observed at the sites of tissue basophils, which, in our opinion, indicated their degranulation. In samples of group II CD15 + granulocytes, CD68 + macrophages and CD117 + tissue basophils were located mainly around the vessels, were single, staining of the components of the dermis was not observed.

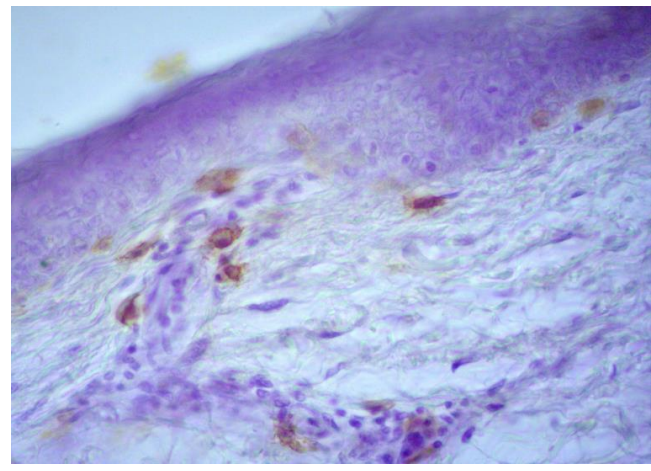

Fig. 4. Numerical CD117+ labrocytes in subepidermal parts of the skin and along blood vessels, group I study. Reaction from MCAB to CD117 / c-Kit Antibody (1C5), ×400

In observations of group I, we found a weak uneven expression of Collagen IV in the basement membranes with its penetration into the dermis, which reflects the violation of their integrity as a result of neck injury (Fig. 5). Compared with the main group in control skin samples, Collagen IV marked the basement membranes of the epithelium and blood vessels, while the reaction was clear, not intermittent, the connective tissue fibers of the dermis remained intact.

The destruction of the collagen of the basement membranes of blood vessels in the compression zone immediately leads to an increase in the permeability of their walls, numerous hemorrhages, inflow from the bloodstream of biologically active substances such as fibrinogen [9, 10]. In fragments of skin taken from the strangulation furrow, we noted its expression in the lumens of blood vessels, endothelial cells, as well as in damaged dermal fibers (Fig. 6).

In all observations of group I of the study, both in the walls of anemic compressed vessels and in the dermis, we observed a pronounced expression of eNOS (Fig. 7). The reaction was heterogeneous: we noticed hyperexpression in the superficial parts of the skin, which is probably due to a more massive tissue injury. 


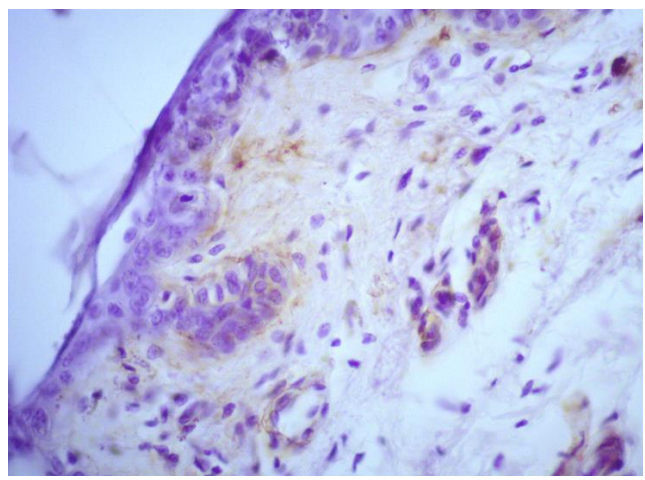

Fig. 5. Weak uneven expression of Collagen IV in the basement membranes of the epidermis and blood vessels, group I study. Reaction from MCAB to Collagen IV (CIV22), $\times 400$

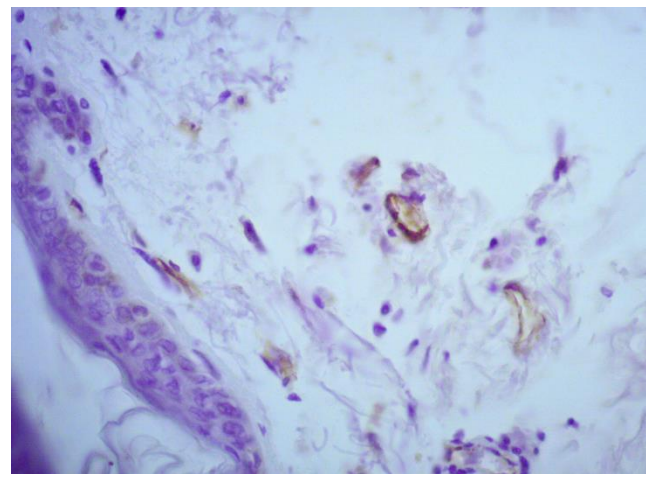

Fig. 6. Moderate expression of Fibrinogen in vascular lumens of skin and endothelial cells, study group I. Reaction from MCAB to Fibrinogen (JG37-18), ×400

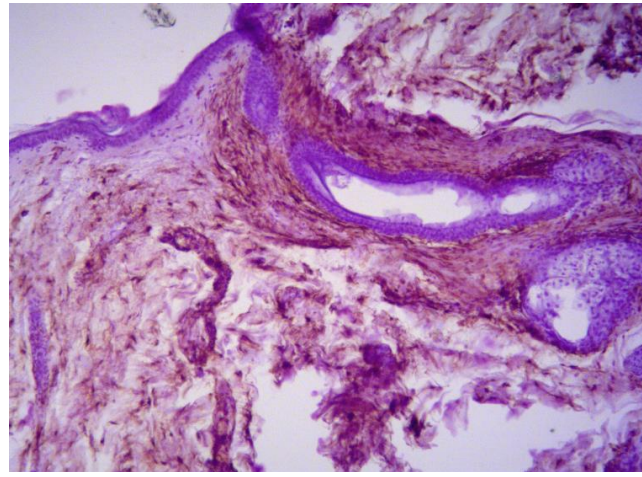

Fig. 7. Hyperexpression of eNOS in endothelial cells, vascular walls, macrophages, deformed dermal fibers, group I study. Reaction with PCAB to anti-eNOS, $\times 100$

In addition to eNOS, we detected induced nitrogen synthase iNOS in the compression zones. Normally, it is found in minimal amounts in macrophages, vascular smooth muscle cells, fibroblasts, epithelium. Activation of iNOS occurs in response to endotoxins and proinflammatory cytokines. Our observations revealed a total staining of the vascular wall (endothelial insole, muscle and serous layer) with the penetration of enzyme proteins between the compact fibers of the dermis (Fig. 8).

In the area of the strangulation furrow in group I of the study, a pronounced positive reaction (3+) of TGF- $\beta 1$ was found in macrophages, endothelial cells of injured vessels (Fig. 9, $\boldsymbol{a}$ ) and in the intercellular matrix of the dermis (Fig. 9, $\boldsymbol{b}$ ).

In the hypodermis, TGF- $\beta 1$ marked vascular walls, fat cells, and fibroblasts.

In the fragments of the control group, endothelial nitrogen synthase of eNOS showed a moderate positive reaction $(2+)$ in vascular endotheliocytes, induced nitrogen synthase of iNOS 
in skin samples of the control group was not detected. Transforming growth factor TGF- $\beta 1$ was determined in single macrophages, fibroblasts and endothelial cells.

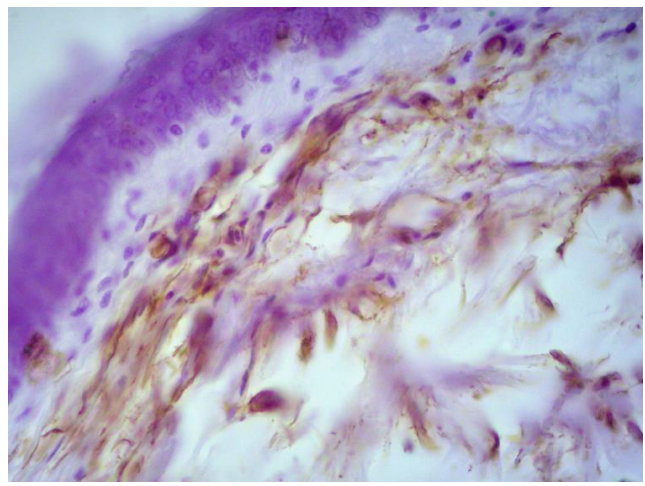

Fig. 8. Expressed expression of iNOS in vascular endothelium, macrophages, dermis fibers, group I study. Reaction with PCAB to anti-iNOS, $\times 400$

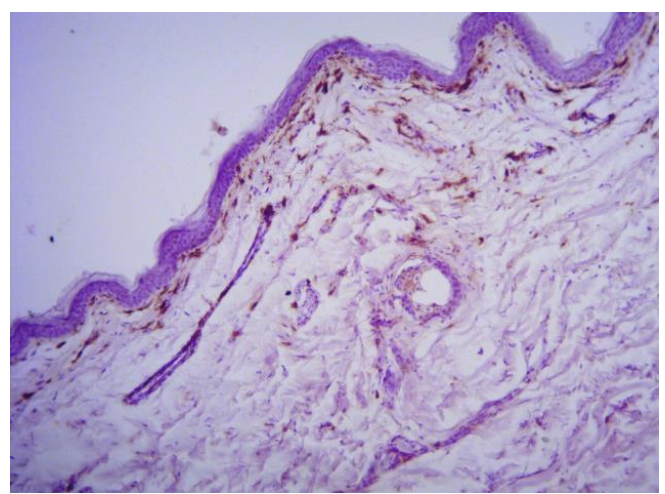

$a$

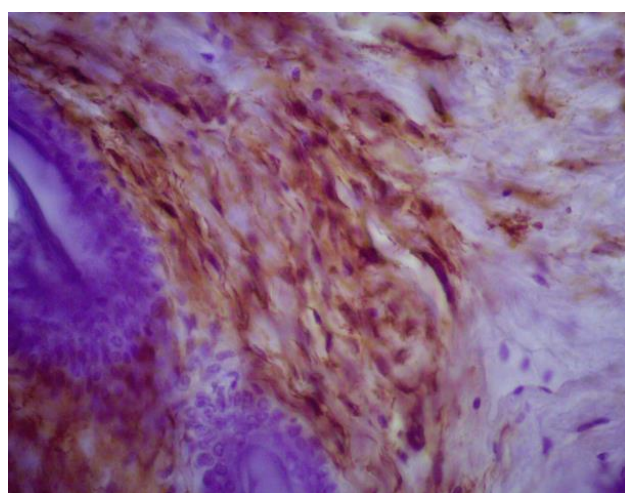

Fig. 9. Reaction with PCAT to TGF- $\beta 1$ Ab-3: $a$ - moderate expression of TGF- $\beta 1$ in macrophages of the subepidermal zone, $\times 100 ; b$ - Expressed expression of TGF- $\beta 1$ in fibroblasts and fibers of the dermis, group I study $\times 400$

\section{Discussion}

The membrane reaction was observed only focially, so the boundaries between the cells were almost indistinguishable. The expression of Cytokeratin pan in deformed epitheliocytes, oriented parallel to the skin surface of the dermis appendages, was also uneven, exclusively cytoplasmic.

Under conditions of hypoxia in mechanical asphyxia, both direct damage to the vascular endothelium and activation of protein substances in the area of skin compression leads to the release of immunocompetent cells from the bloodstream [11]. Usually healthy skin contains single cellular elements: macrophages, T- and B-lymphocytes, which are located mainly in the perivascular region or around the glands.

CD15+ leukocytes, CD68+ macrophages and CD117+ mast cells (labrocytes, mast cells) are included in the skin-associated lymphoid tissue and are important participants in immunological reactions, tissue metabolism, play an important role in the formation of their resistance to various environmental factors $[12,13]$. Even under normal conditions, neutrophil leukocytes are activated in tissues (therefore they are often called tissue leukocytes). They perform their tasks only in interaction with other tissue effector cells, and above all, with macrophages.

Skin macrophages belong to the system of mononuclear phagocytes of loose connective tissue, and in the absence of stimuli are in the dermis and hypodermis in an inactive state. They control tissue homeostasis, as well as provide structuring of the vascular network, participating in the processes of angiogenesis, construction of vascular anastomoses, degradation of the extracellular matrix and 
induction of endothelial cell apoptosis. In case of injury to soft tissues and skin of the neck, they are activated under the influence of interleukins, which are released by granulocytes, and themselves become producers of growth factors, inter- and chemoleukins and other active substances [14, 15].

Tissue basophils, or mast cells, are important cellular components of loose fibrous connective tissue located in all organs and tissues. They develop as a result of differentiation from hematopoietic stem cells of the red bone marrow. The c-Kit receptor is involved in the growth and development of mast cells, and marks it in the IHC CD117 reaction. Activation of the c-Kit determines the regulation of proliferation, apoptosis, adhesion and differentiation in several cell types. Accordingly, the activation of labrocytes under the influence of growth factors, interleukins and others. under conditions of hypoxia leads to an increase in their main function: synthesis and secretion into the surrounding tissue, many biologically active substances such as biogenic amines, histamine, serotonin, dopamine, heparin, hydrolases, prostaglandins [16, 17].

Type IV collagen is a major component of the basement membranes of the epithelium and blood vessels. Together with fibronectin, laminin, glycosaminoglycans, calcium and other substances, these substances determine cell adhesion, elasticity, permeability, colloidal state, electrical charge of the entire epidermis, arteries and veins. Changes in the properties of the basement membrane are primarily the accumulation or loss of Collagen IV cells and are the cause of a number of serious diseases, such as Goodpasture's syndrome, or diabetes [18].

Hypoxia and the breakdown products of neck tissues damaged by hanging increase the permeability of vascular walls and, under conditions of hypercoagulation, activate the transforming growth factor $\beta 1$ and nitrogen synthase.

Endothelial nitrogen synthase eNOS is localized in the plasma membrane of the endothelial cell and has very low normal activity. Like induced nitrogen synthase iNOS, mediates the effects of endothelium-dependent vasodilators, is able to induce apoptosis, is able to modulate the development of the inflammatory response, synthesis of extracellular matrix, inhibits cytokine-stimulated expression of endothelial adhesive molecules and chemotactic peptides; reduces their adhesion to the vascular wall and transformation into macrophages; inhibits platelet aggregation and adhesion; has antioxidant properties. Under the influence of a number of receptor-dependent stimuli (adrenaline, histamine, fibrinogen, $\mathrm{Ca} 2+$ and others), eNOS is displaced from the endothelial cell, seepage into the vessel opening, muscle layer of the wall and adventitia, release outside the bloodstream [19, 20].

TGF- $\beta 1$ is a cytokine that has a pleiotropic effect on the proliferation and differentiation of a wide range of cells, regulating the immune response, cell migration, inflammation, fibrogenesis, angiogenesis, apoptosis in various organs. It is synthesized in almost all cells of the body, but most of it is contained in monocytes and macrophages. TGF- $\beta 1$ is stored in a biologically inactive form in the extracellular matrix and is able to quickly transition to the active form under the influence of acidosis of surrounding tissues during hypoxia, which is due to increased expression in IHC study [21, 22].

Thus, the presence of multiple activated CD15 + granulocytes, CD68 + macrophages and CD117 + mast cells among the fibers of the dermis and hypodermis, weak and uneven expression of type IV collagen in the epidermis and skin vessels with protein infiltration into the surrounding dermis, the presence of endothelial bonds Fibrinogen protein, increased expression of oxidative stress markers eNOS and iNOS, transforming growth factor TGF- $\beta 1$ in endothelial cells, vascular walls, macrophages, the release of these biologically active substances into the surrounding dermis are signs of a lifelong skin reaction to traumatic tissue damage.

The advantages of the results of our research include the subsequent development of a diagnostic algorithm for the needs of the forensic medical expert service. The statement about the lifetime origin of strangulation is more reasoned and scientifically substantiated.

Also, the advantages of using methods of immunomophrology are that, unlike conventional microscopy, with standard staining with hemataxylin and eosin, it is more sensitive to both early immune cell reactions and manifestations of cell apoptosis.

Among the shortcomings, I would like to note the small number of immunohistochemical laboratories, as well as the high cost of research in comparison with classical microscopy.

Study limitations. But besides this, the disadvantages of this method can be attributed to its inefficiency at the initial stages of autolysis and may be completely ineffective in late tissue autolysis. 
Prospects for further research. In further research, an attempt will be made to establish the features of IHC reactions in lung tissue, brain, myocardium in strangulation asphyxia in order to find criteria for its viability and develop a diagnostic algorithm for the needs of forensic expert service.

\section{Conclusions}

Damage to the skin, subcutaneous fat, muscles in the area of strangulation leads to changes in their tinctorial properties. A key part of this process is the violation of the permeability of the vascular wall with the release of reactive immune cells, the release of enzymes, active proteins, plasma, which can be recorded by IHC study and serve as an important diagnostic criterion for strangulation furrow survival. The most informative IHC criteria for the viability of the strangulation furrow can be:

- the presence among the fibers of the dermis of a large number of CD15 + granulocytes, CD117 + labrocytes and CD68 + macrophages;

- decreased expression of type IV collagen in the basement membranes of the epithelium and blood vessels of the skin;

- expression of fibrinogen in the lumens and vascular endothelium;

- expression of markers of oxidative stress - endothelial (eNOS) and induced (iNOS) nitrogen synthase, transforming growth factor TGF- $\beta 1$.

\section{Conflict of interests.}

The authors declare that they have no conflicts of interest.

\section{Financing}

None.

\section{References}

[1] Dziak, L. A., Klyhunenko, O. M. (Eds.) (2019). Mekhanichna asfiksiia. Dnipro: LIRA, 188.

[2] Polutova, N. V., CHesnokova, N. P., Ponukalina, E. V., Bizenkova, M. N. (2017). Asfiksiya: Stadii narusheniya vneshnego dykhaniya, mekhanizmy razvitiya. Nauchnoe obozrenie. Meditsinskie nauki, 2, 57-60.

[3] Viter, V. I., Vavilov, A. Yu., Kungurova, V. V., Babushkina, V. A. (2016). Mekhanicheskaya asfiksiya: sudebno-meditsinskaya diagnostika i otsenka. Izhevsk: GBOU VPO «Izhevskaya gosudarstvennaya meditsinskaya akademiya», 89.

[4] Molin, Y. A., Andreev, A. A., Vorontsov, G. A. (2019). Morphological artifacts in diagnosis of strangulation asphyxia. Russian Journal of Forensic Medicine, 5 (1), 40-41. doi: http://doi.org/10.19048/2411-8729-2019-5-1-40-41

[5] Morales-Ortíz, J., Deal, V., Reyes, F., Maldonado-Martínez, G., Ledesma, N., Staback, F., Washington, A. V. (2018). Platelet-derived TLT-1 is a prognostic indicator in ALI/ARDS and prevents tissue damage in the lungs in a mouse model. Blood, 132 (23), 2495-2505. doi: http://doi.org/10.1182/blood-2018-03-841593

[6] Van Crombruggen, K., Taveirne, S., Holtappels, G., Leclercq, G., Bachert, C. (2018). Innate lymphoid cells in the upper airways: importance of CD117 and IL-1RI expression. European Respiratory Journal, 52 (6), 1800742. doi: http://doi.org/ $10.1183 / 13993003.00742-2018$

[7] Avtandilov, G. G. (2002). Osnovy kolichestvennoy patologicheskoy anatomii. Moscow: Meditsina, 240.

[8] Lisyanyi, N. I., Lisyanyi, A. A. (2018). Neutrophils and oncogenesis. Klinicheskaya onkologiya, 8 (1 (29), 40-45.

[9] Springer, M. S., Guerrero-Juarez, C. F., Huelsmann, M., Collin, M. A., Danil, K., McGowen, M. R. et. al. (2020). Genomic and anatomical comparisons of skin support independent adaptation to life in water by cetaceans and hippos. doi: http://doi.org/ 10.1101/2020.11.15.383638

[10] Zhou, B., Liu, S., He, D., Wang, K., Wang, Y., Yang, T. et. al. (2020). Fibrinogen is a promising biomarker for chronic obstructive pulmonary disease: evidence from a meta-analysis. Bioscience Reports, 40 (7). doi: http://doi.org/10.1042/bsr20193542

[11] Hosseini, J. N., Shahabi, S. H. (2019). Gut Microbiota, Dysbiosis and Immune System; A Brief Review. International Journal of Research in Applied and Basic Medical Sciences, 5 (2), 77-81.

[12] Butov, Yu. S., Skripkin, Yu. K., Ivanov, O. L. (Eds.) (2013). Dermatovenerologiya. Natsioalnoe rukovodstvo. Moscow: GEOTAR-Media, 896.

[13] Mideley, O. D. (2000). Kletochnye mekhanizmy barerno-zaschitnykh funktsiy kozhi i ikh narusheniya pri kozhnoy patologi. Vitebsk: Izdatelstvo Vitebskogo gosudarstvennogo meditsinskogo universiteta, 283. 
[14] Guzik, T. J., Skiba, D. S., Touyz, R. M., Harrison, D. G. (2017). The role of infiltrating immune cells in dysfunctional adipose tissue. Cardiovascular Research, 113 (9), 1009-1023. doi: http://doi.org/10.1093/cvr/cvx108

[15] Castoldi, A., Naffah de Souza, C., Câmara, N. O. S., Moraes-Vieira, P. M. (2016). The Macrophage Switch in Obesity Development. Frontiers in Immunology, 6. doi: http://doi.org/10.3389/fimmu.2015.00637

[16] Heo, S.-K., Noh, E.-K., Kim, J. Y., Jeong, Y. K., Jo, J.-C., Choi, Y. et. al. (2017). Targeting c-KIT (CD117) by dasatinib and radotinib promotes acute myeloid leukemia cell death. Scientific Reports, 7 (1). doi: http://doi.org/10.1038/s41598-017-15492-5

[17] Radu, A., Bejenaru, C., Ţolea, I., Maranduca, M., Brănişteanu, D., Bejenaru, L. et. al. (2020). Immunohistochemical study of CD117 in various cutaneous melanocytic lesions. Experimental and Therapeutic Medicine, 21 (1). doi: http://doi.org/10.3892/ etm. 2020.9510

[18] Lowe, J. S., Anderson, P. G. (2015). Support Cells and the Extracellular Matrix. Stevens Lowes Human Histology, 55-70. doi: http://doi.org/10.1016/b978-0-7234-3502-0.00004-8

[19] Forstermann, U., Sessa, W. C. (2011). Nitric oxide synthases: regulation and function. European Heart Journal, 33 (7), $829-837$. doi: http://doi.org/10.1093/eurheartj/ehr304

[20] Kotiuzhynska, S. G., Umanskiy, D. A. (2017). Endothelial dysfunction in the pathogenesis of vascular accidents in cardiovascular diseases. Zaporozhye Medical Journal, 19 (4), 525-530. doi: http://doi.org/10.14739/2310-1210.2017.4.105305

[21] Zaslavskaya, E. L., Morozov, A. N., Ionin, V. A., Ma, I., Nifontov, S. E., Baranova, E. I. et. al. (2018). The role of transforming growth factor beta-1 and galectin-3 in formation of the left atrium fibrosis in patients with paroxysmal atrial fibrillation and metabolic syndrome. Russian Journal of Cardiology, 2, 60-66. doi: http://doi.org/10.15829/1560-4071-2018-2-60-66

[22] Levkovich, T. V., Pronko, T. P. (2021). Role of the transforming growth factor $\beta 1$ in the genesis of arterial hypertension and its complications. Journal of the Grodno State Medical University, 19 (1), 16-22. doi: http://doi.org/10.25298/ 2221-8785-2021-19-1-16-22

Received date 06.05.2021

Accepted date 20.05.2021

Published date 25.05.2021
(C) The Author(s) 2021

This is an open access article under the Creative Commons CC BY license

How to cite: Dudnyk, V. (2021). Immunohistochemical diagnosis of the viability of the strangulation furrow. EUREKA: Health Sciences, 3, 79-87. doi: http://doi.org/10.21303/2504-5679.2021.001825 